\title{
Institutionalization: \\ A Theory of Human Behavior and the Social Environment
}

\author{
Miriam McNown Johnson \\ Rita Rhodes
}

\begin{abstract}
Institutionalism is the syndrome first recognized and described in inpatient psychiatric facilities, which is now used to describe a set of maladaptive behaviors that are evoked by the pressures of living in any institutional setting. This article traces the development of the theory of institutionalization, which predicts and explains an individual's response to that particular type of environment. The article makes note of key contributors and contributions, and of empirical studies that have advanced the theory. Underlying perspectives and assumptions are identified and earlier theoretical models are reviewed and critiqued. An updated model of the theory, which includes individual vulnerabilities, objective conditions of the institutional placement, and the resident's perceptions of the environment, is presented. New directions in the field of institutional care and implications for social workers, particularly for those working in nursing home and prison settings, are discussed, along with recommendations for next steps for theory progression.
\end{abstract}

\section{Keywords: Institutions, institutionalization, institutionalism, normalization,} deinstitutionalization, nursing homes, prisons

\section{INTRODUCTION}

Conventional wisdom suggests that institutions are no longer an important feature of American life. Two vulnerable populations, however, are likely to experience the effects of institutionalization. America leads the world in the proportion of its citizens who are confined in correctional settings, and improvements in health care suggest that, while Americans are living longer, they are also at increased risk for spending some time in a long-term care facility. In this paper, we present a very brief review of the early history of institutions in America, describe the key contributions to theory development, summarize important empirical studies that have supported and/or progressed the theory, discuss theory components, and end with new directions in institutional care, along with implications for social work.

Miriam McNown Johnson, Ph.D., M.S.W. is associate dean for Academic Affairs and associate professor, College of Social Work; Rita Rhodes, Ph.D. is professor, College of Social Work, University of South Carolina, Columbia, SC, 29208.

Copyright $^{\oplus} 2007$ Advances in Social Work Vol. 8 No. 1 (Spring 2007) 219-236. Indiana University School of Social Work. 


\section{HISTORY}

For the most part, Americans in the Colonial period relied on the services of relatives and neighbors to meet the needs of the poor, the insane, and the orphaned (Rothman, 1971). Criminals were fined, whipped, or hanged-not imprisoned. This pattern was reversed in the mid- $19^{\text {th }}$ century, when there appeared to be a well-intentioned effort to provide a new kind of help for several at-risk populations. Originally conceived as sanctuaries, asylums were established in the countryside with the intention of resocializing and rehabilitating their inmates (including not only prisoners, but also people with mental illness, mental retardation, and dependent children) in a wholesome environment far from the chaos, temptations, and exploitations of the city (Rothman, 1971). Physical separation of the asylum away from the community was consistently practiced.

Eventually, the dreams of institutional effectiveness faded, but the facilities themselves remained, suffering a gradual decline from reform to barely custodial, if not punitive, operation (Rothman, 1971; White \& Wolfensberger, 1969). Despite the efforts of early reformers, including Dorothea Dix (Day, 2003), in the last half of the $19^{\text {th }}$ century, there was a growing perception that it was society, not the institutional residents, that required protection (Rhodes, 1993).

\section{THEORY DEVELOPMENT: KEY CONTRIBUTORS AND CONTRIBUTIONS}

In one of the first professional papers presented or published on the topic in the United States, Myerson (1939) used the term "prison stupor" or "prison psychosis" to describe the "psychologic retreat" that was "enhanced in all directions" by the very care that the mental patients received in the hospitals he visited (p. 1198). Myerson described a "motivation vacuum" and a "physiologic vacuum," both of which existed in the mental hospital setting, and he conducted a two-year experiment at Boston State Hospital that linked a reduction in the number of deaths and an increase in the number of discharges to a "widespread approximation to more normal living," which included more time outdoors, exercise, hydrotherapy, entertainment, and better food.

Bettelheim and Sylvester (1948) studied the impact of institutional placement on children and described a syndrome that they called psychological institutionalism. They considered this to be a "deficiency disease in the emotional sense," stemming from the "absence of meaningful, continuous interpersonal relationships" (p. 191). In the case of children, they were particularly concerned with the impact of "depersonalized rules and regulations," which seemed to lead to emotional impoverishment (p. 191).

Martin (1955) had seen the term institutionalization used in the clinical notes of mental hospitals, where nurses would write "well institutionalized" as an assessment of a patient's adjustment to the hospital setting, implying that the patient "has ceased to rebel against, or to question the fitness of, his position in a mental hospital; he has made a more or less total surrender to the institution life" (p. 1188). In fact, this was considered a positive step for the many mental patients whose condition (e.g., schizophrenia) could not be cured or ameliorated with the remedies available at that time. However, Martin contrasted this phe- 
nomenon to the "true cooperation essential to the success of any treatment" (p. 1188).

Martin (1955) enumerated several potential contributing factors to institutionalism. He suggested that, because the hospital takes care of basic needs, the patient loses the incentive to take responsibility for them; this is the "first step" towards institutionalization. Second, "once in hospital, the patient quickly becomes absorbed into its highly organized life. The fact that any large institution needs an efficient and complex organization carries with it the danger that the life of the individual within it will also become highly organized, and this will tend to relieve him of the need to think or plan for himself in any but the most unimportant trifles" (p. 1189). Third, patients are hesitant "to criticize staff or the organization or from using initiative" out of fear of being sent to an isolation unit. Fourth, rather than inquiring into possible faults of the organization or a personal relationship, which may, in fact, have been the cause of the patient's agitation, staff take the easy way out and send patients to the isolation unit. Fifth, the doctors also foster the institutionalization process, largely unconsciously, due to the pressures of large caseloads and the failure to share their power with lower level staff, who have more direct contact with patients. In addition, although he does not call it staff empowerment, Martin suggested that lack of training in relationship building led the psychiatric nurses to focus on maintaining order in the unit, relying on the authority of the institution for enforcement. He ended his essay on a pessimistic note, suggesting that the authoritarian system that he believed caused the problem was likely to remain unchanged, and his only hope was that psychiatrists would become more aware of it.

Referring to Martin's description of institutionalization, Barton (1959) noted that he preferred the term institutional neurosis, because "it promotes a syndrome to the category of a disease rather than a process" (p. 11). He enumerated seven factors associated with it, including: "loss of contact with the outside world; enforced idleness; bossiness of medical and nursing staff; loss of personal friends, possessions, and personal events; drugs; ward atmosphere; [and] loss of prospects outside the institution" (p. 15). In describing the "ward atmosphere," Martin was clearly referring to the physical environment; he discussed the effects of smell and noise and recommended adding "gay colours, carpets, cushions, and curtains" to "create an air of optimism" (p. 44).

Ellenberger (1960) described the phenomenon using the French term alienization. He compared the process of institutionalization and the results to what happens to wild animals that are captured and put in zoos. (Today, a similar comparison might be made by evolutionary psychologists.) Ellenberger highlighted the "trauma of captivity" and the frustration of the natural territorial and hierarchical instincts of both zoo animals and humans.

Sommer and Witney (1961) focused on one step in the process of institutionalization, the transfer from the "newly admitted ward" to the "continued treatment ward," where there was a less favorable staff-patient ratio and poorer physical surroundings. However, Sommer and Witney saw the transfer as "much more than an administrative act;" the patient was rejected by staff and came to view himself as a "failure," losing hope, and accepting a "passive institutional role" (p. 113). 
Wing (Wing \& Brown, 1961; Wing, 1962) studied institutionalism among chronic mental patients in several hospitals that provided a contrast in social and medical care, concentrating on patients who had been in the hospital for at least two years. He clearly identified three variables related to institutionalism: the social pressures that stem from the institution, the length of time that the resident was exposed to these pressures, and the level of susceptibility that the resident brought.

Using the term social breakdown syndrome to describe types of behaviors in mental patients who appear "more or less independently of the underlying disorder," (p. 1481) Gruenberg (1967) listed seven steps in the process of deterioration. Step four comes with hospital admission and, in step five, the patient learns to comply with the rules to stay out of trouble. In step six, the patient becomes isolated from family and friends. In step seven, the patient identifies with his fellow patients, anticipates staff demands, and strives to "fit in," to "settle down," and to become a "good patient" (p. 1485).

Also, in the mid-20 $0^{\text {th }}$ century, while psychiatrists were describing the experiences of their patients, a number of sociologists were conducting qualitative studies of institutional life (Belknap, 1956; Caudill, 1958; Dunham \& Weinberg, 1960; Goffman, 1958, 1961; Scheff, 1966; Stanton \& Schwartz, 1954; Strauss et al., 1964). The most well known, Goffman, published his findings in a book titled Asylums: Essays on the Social Situation of Mental Patients and Other Inmates (1961). Significantly, he identified the features of total institutions (Goffman, 1958). The four "totalistic features" he listed were:

First, all aspects of life are conducted in the same place and under the same single authority. Second, each phase of the members' daily activity will be carried out in the immediate company of a large batch of others, all of whom are treated alike and are required to do the same thing together. Third, all phases of the day's activities are tightly scheduled, with one activity leading at a prearranged time into the next, the whole circle of activities being imposed from above through a system of explicit formal rulings and a body of officials. Finally, the contents of the various enforced activities are brought together as parts of a single overall rational plan purportedly designed to fill the official aims of the institution (p. 43).

Among the examples of total institutions Goffman cited, in addition to mental hospitals, were TB sanitariums, jails, POW camps, boarding schools, army barracks, monasteries and convents, and ships. Goffman summarized that the central feature of total institutions is that work, recreation, and sleep are experienced in the same place (Goffman, 1959, 1961).

Goffman $(1958,1961)$ also colorfully described admission to the institution as a process of "mortification," where residents are stripped of their social roles and normal identities. The residents then adopt the official or staff view of themselves and try to act out the role of the perfect inmate (1961, p. 63).

Wolfensberger (1972) believed that it was deindividuation that made institutions different from other organizations and residences. The features that charac- 
terize deindividuation include numbers of residents distinctly larger than might be found in a large family, a high level of regimentation, a physical or social environment that aims at a low common denominator, and a place in which all or most of the transactions of daily life are carried out under one roof or on one "campus" (pp. 28-29). Wolfensberger was primarily interested in services for persons with mental retardation, but deindividuation can be found in facilities for other populations as well.

In 1999, Wirt identified four distinctly different explanations, or causal models, for institutionalism. The first, which he called the predisposition model, suggests that institutionalism results from predisposing personal traits when exposed to institutional life. The second, the total institution model, focuses exclusively on the destructive characteristics of institutional life. The asylum model posits that the desire to remain in the hospital is a rational choice from the perspective of the patient. The last model, the symptoms model, identifies institutionalism as either the symptoms of the illness or as the result of years of treatment, regardless of setting.

While psychiatrists and sociologists were exploring the effects of institutional placement on mental patients and people with retardation, others were examining the influence of perceptions of control in the lives of older adults and other nursing home residents. Epidemiological studies conducted in the late 1970s and early 1980s demonstrated that a sense of control was among the most important psychosocial predictors of morbidity, mortality, and psychological well being in older adults (Rodin, 1986; Rowe \& Kahn, 1987.) Baron and Rodin (1978) distinguished between actual control and perceived control; they defined actual control as the ability to influence intended outcomes and perceived control as the expectation of having the power to obtain desired consequences. Also, Rodin (1983) speculated that perceptions of loss of control might be more harmful than perceptions of lack of control.

As people age, acquired deficits in physical and cognitive abilities may induce perceptions of loss of control, as well as actual, objective experiences of loss (Schulz, 1980). An older person's observation of other, less competent older adults through personal contact may lead to modeling of helpless behaviors. It is particularly likely that nursing home residents will be exposed to models of dependency and passivity, in part, because staff members rarely encourage independent activities (Baltes \& Reisenzein, 1986). Inside (and outside) of institutions, people in contact with older individuals tend to offer to assist with tasks they formerly implemented independently. Such assistance, although well-intended, may undermine the individual's sense of control as well as his or her task performance (Avorn \& Langer, 1982; Langer \& Imber, 1979).

Although these theorists were primarily interested in loss of control in old age, the basic concepts could easily be applied to other vulnerable populations (see, for example, Johnson, 1999). In fact, the studies cited in the previous paragraph seem to echo earlier observations of enforced idleness in institutions documented by Barton (1959), Martin (1955), and Wing and Brown (1961). 


\section{EMPIRICAL STUDIES THAT HAVE SUPPORTED AND/OR PROGRESSED THE THEORY}

Given the multitude of factors/features that purportedly contribute to the syndrome of institutionalism and the many symptoms that comprise it, it is not surprising that few studies have examined this topic in its entirety. It may be that there are few recent studies of institutionalism, because several populations that have manifested this syndrome in the past (e.g., orphans, people with developmental disabilities, and chronic mental illnesses) are now, for the most part, either living with families or in small, community-based group homes, or are hospitalized for only brief periods of time. Institutional care of very young children is no longer practiced in this country; empirical studies of the effects of institutional care have focused on more recent practices in Romania. Although research on the effectiveness of various facility characteristics continues in this country, it is not always applicable to institutionalism, as in, for example, Landesman-Dwyer, Sackett, and Kleinman's 1980 study on the effects of size differences among group homes serving the mentally retarded, when the sizes ranged from only 6 to 20 residents.

The two populations that continue to experience care and confinement in relatively large institutional settings are older adults and prisoners. With the latter group, the symptoms of institutionalism (e.g., passivity, compliance) are not perceived as problematic. For older adults, alternative models of care are being developed and evaluated (see below).

In addition, researchers conducting sophisticated empirical studies face the practical challenges of finding institutions that are willing and able to cooperate with the implementation of experimental conditions, randomly assigning subjects to various treatment conditions, identifying control groups, and controlling other threats to internal validity, including diffusion/contagion of interventions across groups and reactivity (the Hawthorne effect).

\section{KEY EMPIRICAL STUDIES FOUND IN THE LITERATURE}

The four models that Wirt (1999) identified, which are discussed above, are strongly linked to research findings. The predisposition model was supported by several early studies, including Wing and Brown (1970) and Liberkakis (1981). Wing and Brown, who examined 273 hospital patients with mild-to-moderate mental illness, found that patients with schizophrenia were particularly susceptible to institutionalism, "because of their vulnerability to understimulation" (p. 184). Liberkakis studied 324 mental patients; he found that low intelligence, poor education, and disabilities were significantly associated with institutionalism.

In two longitudinal studies of patients in mental hospitals, Wing and his colleague (Wing \& Brown, 1961; Wing, 1962) found data to support the total institution model, with length of stay being one major predictor variable, and the length of time during the day that a patient spent doing absolutely nothing a second variable. In his often-cited ethnographic study of conditions and staff behaviors inside a mental hospital, Rosenhan (1973) concluded that "neither anecdotal nor 'hard' data can convey the overwhelming sense of powerless which invades the individual as he is continually exposed to the depersonalization of the psychiatric hospital” (p. 198). 
Concerned about the effects of living in a "virtually decision-free environment," Langer and Rodin (Langer \& Rodin, 1976; Rodin \& Langer, 1977) conducted an experimental study and follow-up on the effects of an intervention to increase feelings of choice and personal responsibility in 91 elderly nursing home residents. Nurses' rating and health-and-mortality indicators documented significant improvement in the experimental group on measures of alertness, active participation, and sense of well-being that persisted beyond 18 months. Subsequent studies (e.g., Skea \& Lindesay, 1996; Stirling \& Reid, 1992) documented similar results.

Studies examining the effects of a more "normalized" environment within an institutional setting include Myerson's (1939) classic experiment in a public mental hospital, (described above), Eyman, Demaine, and Lei's (1979) work with facilities for people with mental retardation (1979), and preliminary findings on the Eden Alternative model reported in a study by Coleman et al. (2002). Eyman, Demaine, and Lei found positive changes in adaptive behavior in 245 developmentally-disabled individuals living in family-care homes and board-and-care homes, using the Wolfensberger and Glenn's Program Analysis of Service Systems (PASS) instrument (1975) to measure the conformity of service systems to normalization principles. Coleman et al. found "no beneficial effects" of the Eden Alternative in terms of cognition, functional status, or survival, although qualitative observations indicated that "the change was positive for many staff as well as residents" and implied that longer term follow-up might provide additional positive results (p. M422).

Dependent variables in empirical studies of the asylum model include patients' attitudes, "attraction to the hospital," and desires related to discharge or readmission. In his study of 358 institutionalized male veterans, Goldman (1965) found that "a sizeable segment of the population was found to have no substantial interest in ever returning to the community" (p. 322). Weinstein (1979) reviewed 38 quantitative studies of patients' attitudes toward mental hospitals and found that favorable attitudes predominated in $79 \%$ of them. Using a sample of 187 aftercare patients, Drake and Wallach (1992) found a preference for living in the hospital was associated with past hospital stays, symptoms of psychosis, and severe drug abuse. In a study of patients readmitted to the Bronx State Hospital, Rosenblatt and Mayer (1974) found that patients with a greater number of previous admissions were more likely to return to the hospital, independent of the severity of their illness. After concluding their study, Rosenblatt and Mayer reviewed two dozen other studies on recidivism and found "strikingly consistent patterns" in patient movement with 36 different populations: the more often they had been admitted, the more likely they were to return. In a recent study, Rosenheck and Neale (1998) linked reduction in hospital utilization with intensive community treatment, using data from nine VA hospitals over a five-year period, suggesting that the desire to stay in or return to the hospital is based on community deficits as much as institutional ones.

The symptoms model appears to dismiss institutionalism out of hand. Mathai and Goppinath (1985) found that hospital care does not have a significant influence on the deficits associated with chronic schizophrenia, based on their study 
of 80 chronic schizophrenic and 16 manic-depressive psychotic patients; they concluded that, symptoms sometimes attributed to institutionalism are an integral feature of the disease process, rather than a result of institutionalization. Making the same point, Davidson et al., (1995) concluded that diagnosis, rather than residential situation, was most likely to account for negative symptoms.

\section{THE THEORY OF INSTITUTIONALIZATION: CONCEPTS, ASSUMPTIONS, AND MODEL}

\section{Definitions of Concepts}

Institutions are facilities where residents exercise little or no choice about their participation in activities, have little input into how they are treated, and cannot leave without being officially released or discharged. Lack of control over one's life is a major feature of institutions; the residents' needs are usurped by the needs of the institution. Goffman (1961) defined a total institution as "a place of residence and work where a large number of like-situation individuals, cut off from the wider society for an appreciable period of time, together lead an enclosed, formally administered round of life" (p. xiii). Usually, total institutions attempt to resocialize the residents to become more compliant and accepting of institutional and societal norms.

We define institutionalism as the syndrome (group of symptoms) that results from the process of institutionalization. It is characterized by apathy, lethargy, passivity, and the muting of self-initiative, compliance and submissiveness, dependence on institutional structure and contingencies, social withdrawal and isolation, an internalization of the norms of institutional culture, and a diminished sense of self-worth and personal value (Belcher \& Rife, 1989; Bettelheim \& Silvester, 1948; Haney, 2001; Wirt, 1999).

\section{Underlying Perspectives and Assumptions}

As a theory, institutionalization fits clearly with the assumptions of the ecosystems perspective. A focus on the importance of the perceptions of those living in controlled environments, in addition to the objective conditions themselves, suggests the relevance of a social constructionist perspective as well.

Ecosystems introduces the construct of goodness-of-fit, the extent to which there is a match between an individual's needs, rights, goals, and capacities and the qualities of his or her physical and social environment (Germain \& Gitterman, 1995, p. 817; Greene, 1999, p. 299). Lawton and Nahemow (1973) postulated a two-dimensional model of "competence and environmental press" to illustrate the negative affect and maladaptive behavior that results when personal characteristics and environmental demands are mismatched. Institutionalization theory suggests that it is this mismatch, or lack of goodness-of-fit between residents and their institutional environment, that is the primary cause of the syndrome of institutionalism.

In addition to the objective reality of the setting, the residents' perception of the environment and their experiences, contribute to the development of the syndrome. In addition, according to labeling theory, labels such as patient or criminal may result in institutional residents accepting and internalizing the attributes 
of those roles. The impact of labeling is not limited to the label recipient, but it extends to those with whom she or he interacts. For example, once a person is labeled a psychiatric patient, staff may interpret even normal behaviors as symptoms of mental illness (Rosenhan, 1973).

\section{A Theoretical Model}

Wirt (1999, p. 264) believed that the four models he described (predisposition, total institution, asylum, and symptoms) were "competing and sometimes antithetical explanations for institutionalism." We partially concur, noting that the symptom model dismisses institutionalism out of hand. The asylum model, which focuses on the desire to return to or remain in the institution, appears to be related to institutionalism, often occurring simultaneously, but may, in fact, be a separate phenomenon, particularly as it is postulated to be based on rational choice. We are thus left with the predisposition model and the total institution model, which could easily be construed as complementary. These two models, however, do not clearly or fully incorporate the effects of residents' perception.

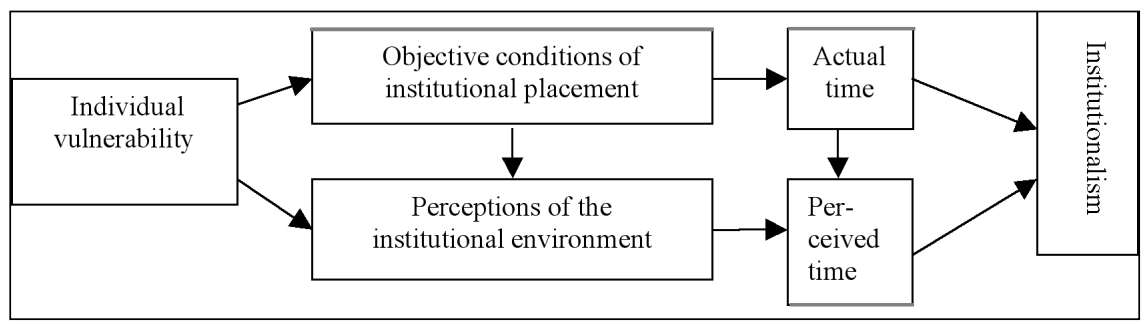

Figure 1. A graphic illustration of how individual vulnerability, multiplied by conditions in the institutions and the resident's subjective perceptions of it, over time, results in institutionalism.

A synthesis of hypotheses and empirical findings presented here suggests support for a theoretical model of institutionalization as illustrated in Figure 1. It is comprised of five constructs: four contributing factors, including individual vulnerability, the conditions of institutional settings, resident perceptions of the institutional environment, and time in care, and the outcome, the syndrome of institutionalism.

The individual brings to the institution certain vulnerabilities, such as poor health, limited coping skills, lack of a social support network, or mental illness. The institutional setting then imposes certain demands upon the individual. These include the surrender of personal identify at admission. With longer-term care, this is followed by isolation, regimentation, and deindividuation. The effects of the objective or actual situation are magnified by the resident's perception of events, including loss of control and fear of punishment or retribution. This is then exacerbated by the actual length of time spent in the institution, as well as the resident's perception that there is little or no hope of discharge. 
The fact that institutionalism is not manifested by all vulnerable persons in different situations or by all individuals in controlled environments supports the thesis that it is the combination of extremes in some or all of these factors that produces the syndrome. So, for example, it is not surprising that the syndrome was observed commonly, if not invariably, in persons with schizophrenia who were locked for years in the back wards of state mental hospitals. On the other hand, young, mentally and physically healthy, well-trained military personnel who are captured and detained in deplorable conditions in POW camps usually do not manifest the symptoms of institutionalism, although they may suffer from other syndromes, such as PTSD.

\section{Variables}

A review of empirical studies on institutionalization and related topics reveals a number of independent and dependent variables that have been used to study this topic. We would suggest that the following variables, listed under the five constructs of the theory, are positively correlated with the probability of the development of institutionalism.

Individual vulnerability: very young or very old age, poor physical health, compromised cognitive functioning, psychiatric illness, lack of a strong social network, poor coping skills, lack of mobility, and low self-efficacy. We should note, however, that even without identified deficits, all people have basic human needs that leave them vulnerable to extreme environments. Wirt suggests, "the restrictive environment of institutional settings coupled with oppressive staff [are] capable of producing institutionalism in almost any person regardless of diagnosis, predispositions, or personality" (1999, p. 260).

Characteristics of the institution: confiscation of personal belongings, large size (resident capacity), isolated location, authoritarian staff, low staff to resident ratio, lack of staff training, disempowerment of staff, rigidity of routine, drab or standardized physical environment, lack of stimulation, enforced idleness, lack of choice and control, lack of privacy, program or unit designated for long-term residents, and absence of meaningful relationships.

Resident perceptions: lack of input into the placement decision, mortification, loss of identity, acceptance of patient or inmate label, isolation, loss of control, loss of sense of purpose, expectation of lengthy or permanent stay.

Institutionalism can be measured by the manifestation of its symptoms, which were also listed above: apathy, lethargy, passivity, and the muting of self-initiative; compliance and submissiveness; dependence on institutional structure and contingencies; social withdrawal and isolation; an internalization of the norms of institutional culture; and a diminished sense of self-worth and personal value.

Based on our understanding of the literature, we suggest that the features and characteristics within each construct are additive or cumulative. For example, a person might have multiple vulnerabilities, or an institution might have some but not all of the characteristics listed. We further hypothesize that the contributing constructs have a multiplicative effect on each other. In other words, each has a magnifying effect, rather than simply adding to the others. We also hypothesize 
that there is a threshold or critical mass of effects that, once achieved, results in manifestation of the syndrome.

\section{NEW DIRECTIONS IN INSTITUTIONAL CARE}

In response to criticisms of institutions, different theoretical models, and research findings, several alternative models of care and treatment have been proposed and implemented. Most of these directly address the limitations of institutions that were summarized above.

\section{Normalization}

The normalization model was proposed in the late 1960s (Nirje, 1994; Wolfensberger, 1972). In simple terms, normalization means making available to institutionalized people living arrangements that closely resemble those enjoyed by other citizens. This approach suggests that facilities should be small (i.e., designed for no more than six to eight residents). They should resemble valued homes in the community-there should be no signs in front that identify the residents inside as different from other citizens. Facilities should be integrated into the community so that residents can walk to or have available public transportation to the library, shopping centers, movie theaters, and parks. Residents should work and/or receive services away from the facility. There should be a continuum of options available, but residents should not have to move simply because their needs change; instead, services should be adapted so that residents can experience a sense of permanence and security in their living arrangement.

The 1980 Americans with Disabilities Act provided unequivocal federal support for the integration of persons with disabilities into the mainstream of American life. For several decades now, most people with disabilities have lived with their families or resided in community-based facilities, including intermediate-care facilities, foster homes, group homes, boarding homes, and supervised apartments (Segal, 1995). In 1997, 194,968 people with mental retardation were living in homes with one to six people; the average proportion of developmentally-disabled individuals living in settings of only one to six persons nationwide is $56.9 \%$, with Vermont having the highest level at $100 \%$, and Arkansas at the lowest, with only $10 \%$ according to data from The Arc (the national advocacy organization for retarded citizens) (Davis, 1998). Medicaid pays for a wide range of services and living arrangements for persons with IQs below 60 or those with an IQ between 60 and 69 who have an additional handicapping condition of cerebral palsy, spina bifida, Prader-Willi syndrome, epilepsy, or autism.

Studies of small, community-based group homes for people with mental retardation show that the community care movement has been largely successful (Landesman-Dwyer, 1982; Community Living, 1997). This has provided an impetus for human service providers to develop small, community-based group homes for other populations with special needs (e.g., people with chronic mental illnesses, newly released prisoners, and acting-out adolescents).

\section{Residential Facilities for Children}

At the same time that persons with developmental disabilities were being moved into community-based care, there was also strong federal support for efforts to 
return children in out-of-home care to their families or to find permanent adoptive homes for them, as codified in the Adoption Assistance and Child Welfare Act of 1980 (PL 96-272) (see Johnson \& Harrison, 1994). Nevertheless, the rate of institutionalization of children has remained relatively stable. Schwartz (in Gambrill \& Stein, 1994) reports that "the boundaries between child welfare, juvenile justice, and mental health systems are porous" (p. 276) and that, as reforms and changing policies lead to the closing of institutions under one auspice, corresponding increases appear in the others.

During the mid-1990s, there was a renewed interest in congregate group care for socially- and economically-disadvantaged children and those who suffered instability due to multiple disrupted placements with relatives and foster families (McKenzie, 1996; Van Biema, 1994; Schuh \& Caneda, 1997; Weisman, 1994). This may have been sparked, in part, by a speech by Newt Gingrich, who suggested that the babies of unwed teen mothers be put in orphanages (Van Biema, 1994). At the same time, child advocates and professionals were debating the question (Gambrill \& Stein, 1994), with those opposed noting that child-caring institutions were ineffective and costly "while there is a need for a small number of facilities for violent and chronic delinquents and for children and youth who [have other serious problems] ... the number needing such care is very small in comparison to the hundreds of thousands placed into institutions each year" (Schwartz, in Gambrill \& Stein, 1994, p. 276).

Although family foster homes and small group homes provide a majority of outof-home care for children and youth, placement in more restrictive settings remains a common occurrence. Using a national probability sampling design, James et al. (2006) have documented that $25 \%$ of youth experience an "intensive or restrictive setting during their first out-of-home care episode" (p. 96). McMillen et al. (2004) found that three-quarters of youth still in out-of-home care at age 17 had been in residential care facilities and nearly half of them had experienced episodes in inpatient psychiatric care.

There are few, if any, orphanages left in America, but they remain a significant part of the child welfare systems in other countries. Extensive studies of the effects of institutional rearing in Romanian orphanages (see Kadlec, 2002; Ellis, 2004; Parker \& Nelson, 2005; Tarullo, 2005) document stunted physical growth, persistent socio-emotional deficits, and even disruptions in the development of neural circuitry in the brains of young children.

\section{Deinstitutionalization}

The deinstitutionalization movement arose in the 1960s and early 1970s in response to a series of trends, including increasing public awareness of the negative effects of institutionalization, growing costs of institutional care, scientific advances that made confinement in institutions obsolete, political, and legal pressures to treat residents in the least restrictive manner, and the development of SSI payments directly to clients (Segal, 1995). What was originally conceptualized as a solution to institutionalization eventually became a problem in and of itself, as individuals were moved from one dominant institutional form to another as many community-based nursing homes and groups homes, bowing to the pressures of economy of scale, have come to resemble the institutions they were intended to 
replace (Segal, p. 710). A lack of funding has left many communities short of resources.

An example of a failure of deinstitutionalization for mentally ill people is the large numbers who are incarcerated in jails and prisons with no provision for mental health services. This problem has been recognized for more than 25 years (see Briar, 1983). With 3000 inmates receiving psychiatric services, the Los Angeles County jail system is said to be the largest mental institution in the United States (Izumi, Schiller, \& Hayward, 1996). It is estimated that, as many as $20 \%$ of prisoners have a mental or psychological disorder or a developmental disability (Haney, 2001). Of the 10 million adults booked into local jails each year, approximately 700,000 have active symptoms of mental illness (The Sentencing Project, 2002). Most mentally ill offenders are arrested for minor offenses, such as trespassing, vagrancy, urinating in public, or shoplifting at the corner convenience store. Many of them also have substance abuse problems but cannot get into drug- and alcohol-treatment programs because of their mental illnesses. It has been documented that, due to budget cuts and lack of space in state mental health hospitals, some mentally ill individuals may remain in jail for up to two years-even with court intervention—before being admitted to a more appropriate facility (Bell, 2002).

\section{The Eden Alternative}

With a growing population of older adults, and particularly those older than 85 , many more people are living in institutions designed to care for those experiencing the debilitating effects of very old age. A new model of care for older adults is called the Eden Alternative (Thomas, 1994; Weinstein, 1998). This approach was developed in response to the common, sterile, treatment-orientation of nursing homes that often results in loneliness, helplessness, and boredom according to Eden Alternative founder William Thomas. He enumerates three fundamental principles of this new kind of care: acknowledging each resident's capacity for growth, focusing on the needs of the residents rather the needs of the institution, and emphasizing quality long-term nurturing care, while providing short-term treatment as needed (Thomas, 1994). This new philosophy of care involves normalizing the physical environment of facilities with the addition of pets, plants, and children; placing the maximum possible decision-making authority in the hands of residents and those who care for them; de-emphasizing program activities by encouraging resident involvement in the daily routine of the facility; and de-emphasizing the use of prescription drugs.

In the Eden Alternative, Thomas specifically addresses staff empowerment. Several early theorists (Barton, 1959; Goffman, 1961; Martin, 1955; Myerson, 1939) noted that institutionalization affects staff (e.g., ward attendants, nurses, doctors) as well as residents. Martin said, "the staff become victims of the system" and he believed that finding staff who were "sufficiently independent and integrated" to resist the process of institutionalization was "pure fantasy" (p. 1190). Thomas believes he has found the answer to Martin's dilemma.

\section{The Green House Project}

Furthering development of his vision, Thomas has now launched the National Green House Project, a radical shift away from large institutions for older adults to 
homes with no more than 10 residents each (Hamilton, 2005; Kalb \& Juarez, 2005; Mosheim, 2006, Rabig et al., 2006; Thomas, 2004). This model responds positively to the research on perceptions of control (Avorn \& Langer, 1982; Langer \& Rodin, 1976). Green House facilities continue the Eden Alternative principles of emphasizing residents' competence through encouraging participation in daily household activities, such as cooking and gardening. A redesigned staff pattern allows the specially-trained certified nursing aides (now called shahbazim) to provide more holistic care and to take a larger role in decision-making. A two-year evaluative study of Green House outcomes is underway (Rabig et al., 2006).

\section{Prisons}

According to a Bureau of Justice bulletin (Harrison \& Beck, 2007), the total number of prisoners in the United States at the end of 2005 was 2,320,359; one in every 136 American residents was in prison or jail. This reflected an average rate of growth of $3.1 \%$ per year since 1995. It was in that year that the United States became the world's leader in incarceration rates, a position it retains to this day.

While new models are being tried in the care of older adults, the American correctional system is moving in the opposite direction (Frost, 2006). There continues to exist widespread support for large, monolithic prisons and "the idea that control of prisoners means providing as miserable an existence as possible" (Cook, 2001 , p. 30). Rehabilitation is largely absent in correctional institutions in the United States; instead, the prison, as an institution, is used solely to punish. The worst excesses of total institutions are found in today's "Supermax" (super-maximum-security) prisons, where inmates are typically in solitary confinement for 23 hours a day in small, windowless cells, with no privacy (they are constantly monitored by video cameras), no work, no educational opportunities, and very limited access to recreation or visitors.

\section{CONCLUSION}

\section{Next Steps for Theory Progression}

We have several recommendations for next steps. First, the Eden Alternative, the Green House model, and other residential alternatives to nursing home care can be studied holistically, in addition to investigating smaller scale interventions, such as those studied by Rodin and Langer, cited above. As the population ages, it is important that this type of research be supported and carried out. Second, institutionalism in prisons is not well understood and is long overdue for intensive study. Although prisonization, which implies a more oppositional stance towards the institution (Haney, 2001), has received some attention, institutionalism and its relation to recidivism, has not. Third, the theoretical model proposed in this article should be tested in a variety of institutional settings.

\section{Implications for Social Work}

The profession of social work has a long history of being involved with institutional care and confinement of vulnerable populations. Many social workers are, or will be, employed in large, group-care settings (Ginsberg, 2001). As part of their job responsibilities, they may be called upon to advocate for the rights and needs of their clients, as well as for vulnerable populations in other institutional settings. 
Because many clients in institutional setting are involuntary, social workers have a special ethical responsibility to them. Often, "it is social workers who must inform those who have been institutionalized or who face institutionalization of their rights or interpret their rights for them. Many times only social workers are available to act as advocates for those who are institutionalized, insuring that their rights are recognized and respected" (Saltzman \& Proch, 1990, p. 360). In a corrections context in particular, but also in other institutional settings, social workers must be prepared to advocate "for safe, humane, and equitable treatment of all individuals" (NASW, 2000, p. 57). Understanding the process and effects of institutionalization will help social workers perform these functions.

\section{References}

Avorn, J., \& Langer, E.J. (1982). Induced disability in nursing home patients: A controlled trial. Journal of the American Geriatric Society, 30, 397-400.

Baltes, M.M., \& Reisenzein, R. (1986). The social world in long-term care institutions: Psychosocial control toward dependency? In M.M. Baltes and P.B. Baltes, (Eds)., The psychology of control and aging. Hillsdale, NJ: Erlbaum.

Baron, R., \& Rodin, J. (1978). Perceived control and crowding stress. In A. Baum, J.E. Singer, and S. Valins (Eds.) Advances in environmental psychology (pp. 145-190). Hillsdale, NJ: Erlbaum.

Barton, R. (1959). Institutional neurosis. Bristol: John Wright \& Sons LTD.

Belcher, J.R., \& Rife, J.C. (1989). Social breakdown syndrome in schizophrenia: Treatment implications. Social Casework: The Journal of Contemporary Social Work, 70, 611-616.

Belknap, I. (1956). Human problems of a state mental hospital. New York: McGraw-Hill.

Bell, N.M. (2002, October 31). Mentally ill inmate will move to hospital. The State [Columbia, SC], p. B3.

Bettelheim, B., \& Sylvester, E. (1948). A therapeutic milieu. American Journal of Orthopsychiatry, 18, 191206.

Briar, K.H. (1983). Jails: Neglected asylums. Social Casework: The Journal of Contemporary Social Work, 64(7), 387-393.

Caudill, W. (1958). The psychiatric hospital as a small society. Cambridge: Harvard University Press.

Chassin, L., Presson, C.C., Young, R.D., \& Light, R. (1981). Self-concepts of institutionalized adolescents: A framework for conceptualizing labeling effects. Journal of Abnormal Psychology, 90(2), 143-151.

Coleman, M.T., Looney, S., O’Brien, J., Ziegler, C., Pastorino, C.A., \& Turner, C. (2002). The Eden Alternative: Findings after 1 year of implementation. Journal of Gerontology, 57A(7), M422-M427.

Community living. (1997). Retrieved January 15, 2007, from The Arc, http://www.thearc.org/faqs/comlilv.html.

Cook, J.R. (2001). Asphalt justice: A critique of the criminal justice system in America. Westport, CT: Praeger Publishing.

Davidson, L., Hoge, M.A., Merrill, E., Rakfeldt, J., \& Griffith, E.E. (1995). The experience of long-stay inpatients returning to the community. Psychiatry, 58, 122-132.

Davis, S. (1998, October). A status report on inclusion of people with mental retardation in community housing. Retrieved February 2, 2007 from http://www.thearc.org/report/98WAITLS.html.

Day, P.J. (2003). New history of social welfare (4 $4^{\text {th }}$ ed). Boston, MA: Allyn \& Bacon.

Drake, R.E., \& Wallach, M.A. (1992). Mental patients' attraction to the hospital: Correlates of living preference. Community Mental Health Journal, 28, 5-13.

Dunham, H.W., \& Weinberg, S.K. (1960). The culture of the state mental hospital. Detroit, MI: Wayne State University. 
Dyer, J. (2000). The perpetual prisoner machine: How America profits from crime. Boulder, CO: Westview Press.

Ellenberger, H.F. (1960). Zoological garden and mental hospital. Canadian Psychiatric Association Journal, 5, 136-149.

Ellis, B.H., Fisher, P.A., \& Zaharie, S. (2004). Predictors of disruptive behavior, developmental delays, anxiety, and affective symptomatology among institutionally reared Romanian children. Journal of American Academy of Child and Adolescent Psychiatry, 43, 1283-1292.

Eyeman, R., Demaine, G.C., \& Lei, T-J. (1979). Relationships between community environments and resident changes in adaptive behavior: A path model. American Journal of Mental Deficiency, 83(4), 330-338.

Frost, N.A. (2006). The punitive state: Crime, punishment, and imprisonment across the United States. New York: LFB Scholarly Publishing.

Gambrill, E.D., \& Stein, T.J. (1994). Controversial issues in child welfare. Boston: Allyn \& Bacon.

Germain, C.B. (1973). An ecological perspective in case-work practice. Social Casework, 54, 323-330.

Germain, C., \& Gitterman, A. (1995). Ecological perspective. In R.L. Edwards et al. (Eds.), Encyclopedia of Social Work, (19 ${ }^{\text {th }}$ ed., Vol. 1, pp. 816-824). Washington, D.C.: NASW Press.

Ginsberg, L.H. (2001). Careers in social work ( $2^{\text {nd }}$ ed.). Boston: Allyn \& Bacon.

Goffman, E. (1961). Asylums: Essays on the social situation of mental patients and other inmates. Garden City, NY: Anchor Books.

Goffman, E. (1958). Characteristics of total institutions. In Symposium on Preventive and Social Psychiatry (pp. 43-93). Washington, D.C.: Walter Reed Army Institute of Research.

Goldman, A.R. (1965). Wanting to leave or to stay in a mental hospital: Incidence and correlates. Journal of Clinical Psychology, 21, 317-322.

Greene, R.R. (1999). Ecological perspectives: An eclectic theoretical framework for social work practice. In R.R. Greene (Ed.), Human behavior theory and social work practice ( ${ }^{\text {nd }}$ ed., pp. 259-300). New York: Aldine de Gruyter.

Gruenberg, E.M. (1967). The social breakdown syndrome: Some origins. The American Journal of Psychiatry, 123, 1481-1489.

Hamilton, W.L. (2005, April 23). The new nursing home, emphasis on home. New York Times. Retrieved April 25, 2005 from http://www.nytimes.com

Haney, C. (2001, December). The psychological impact of incarceration: Implications for post-prison adjustment. Retrieved January 15, 2007 from http://aspe.hhs.gov/HSP/prison2home02/Haney.htm

Harrison, W.D., \& Johnson, M. (1994). Child welfare policy in the United States. Social Policy and Administration, 28, 139-150.

Izumi, L.T., Schiller, M., \& Hayward, S. (1996). Corrections, criminal justice, and the mentally ill: Some observations about costs in California. San Francisco: Pacific Research Institute.

James, S., Leslie, L.K., Hurlburt, M.S., Slymen, D.J., Landsverk, J., Davis, I., Mathiesen, S.G., \& Zhang, J. (2006, Winter). Children in out-of-home care: Entry into intensive or restrictive mental health and residential care placements. Journal of Emotional and Behavioral Disorders, 14, 196-208.

Johnson, M.M. (1999.) Managing perceptions: A new paradigm for residential group care. Child \& Youth Care Forum, 28, 165-179.

Kadlec, M.B., \& Cermak, S.A. (2002). Activity level, organization, and social-emotional behaviors in postinstitutionalized children. Adoption Quarterly, 6, 43-57.

Kalb, C., \& Juarez, V. (2005, August 1). The newest thing in end-of-life care: Residences that look and feel like the house you've lived in all your life. Newsweek, 46-47.

Landesman-Dwyer, S. (1981). Living in the community. American Journal of Mental Deficiency, 86, 223234

Landesman-Dwyer, S., Stein, J.G., \& Sackett, G.P. (1978). A behavioral and ecological study of group homes. In G.P. Sackett (Ed.), Observing behavior, Volume I: Theory and applications in mental retardation. Baltimore: University Park Press. 
Langer, E.J., \& Imber, L. (1979). When practice makes perfect: The debilitating effects of overlearning. Journal of Personality and Social Psychology, 37, 2014.

Langer, E.J., \& Rodin, J. (1976). The effects of choice and enhanced personal responsibility for the aged: A field experiment in an institutional setting. Journal of Personality and Social Psychology, 34, 191-198.

Lawton, M.P., \& Nahemow, L. (1973). Ecology of the aging process. In C. Eisdorfer \& M.P. Lawton (Eds.), The Psychology of Adult Development and Aging (pp. 619-674). Washington, D.C.: American Psychological Association.

Martin, D.V. (1955). Institutionalization. Lancet, 2, 1188-1190.

Maslow, A.H. (1954). Motivation and personality. New York: Harper \& Row.

McKenzie, R.B. (1996). Orphanages: the real story. In the Public Interest, 123, 100-104.

McMillen, J.C, Scott, L.D., Zima, B.T., Ollie, M.T., Munson, M.R., \& Spitznagel, E. (2004). Use of mental health services among older youths in foster care. Psychiatric Services 55, 811-817.

Mosheim, J. (2006). Long-term care: Alternative approach empowers staff, residents. Advance, 16(22), 6-8, 50.

Myerson, A. (1939). Theory and principles of the "total push" method in the treatment of chronic schizophrenia. American Journal of Psychiatry, 95, 1197-1204.

Myles, J.F. (1978). Institutionalization and sick role identification among the elderly. American Sociological Review, 43, 508-521.

Nirje, B. (1994). The normalization principle and its human management implications. SRV-VRS: The International Social Role Valorization Journal, 1(2), 19-23.

Parker, S.W., \& Nelson, C.A. (2005, January). The impact of early institutional rearing on the ability to discriminate facial expressions of emotion: An event-related potential study. Child Development, 7(1), 5472

Rabig, J., Thomas, W., Kane, R.A., Cutler, L.J., \& McAlilly, S. (2006). Radical redesign of nursing homes: Applying the green house concept in Tupelo, MS. The Gerontologist, 46, 533-539.

Rhodes, R. (1993). Mental retardation and sexual expression: An historical perspective. Journal of Social Work \& Human Sexuality, 8(2), 1-27.

Rodin, J. (1983). Behavioral medicine: Beneficial effects of self-control training in aging. International Review of Applied Psychology, 32, 153-181.

Rodin, J. (1986). Aging and health: Effects of the sense of control. Science, 233, 1271-1276.

Rodin, J., \& Langer. E. (1977). Long-term effects of a control-relevant intervention with the institutionalized aged. Journal of Personality and Social Psychology, 3, 897-902.

Rosenblatt, A., \& Mayer, J.E. (1974). The recidivism of mental patients: A review of past studies. American Journal of Orthopsychiatry, 44, 697

Rothman, D.J. (1971). The discovery of the asylum. Toronto: Little, Brown \& Company.

Rowe, J.W., \& Kahn, R.L. (1987). Human aging: Usual and successful. Science, 237, 143-149.

Scheff, T.J. (1966). Being mentally ill: A sociological theory. New York: Aldine.

Segal, S.P. (1995). Deinstitutionalization. In R.L. Edwards et al. (Eds.), Encyclopedia of Social Work, (19 ${ }^{\text {th }}$ ed., Vol. 1, pp. 704-712). Washington, D.C.: NASW Press.

Sentencing Project, The. (2002). Mentally ill offenders in the criminal justice system: An analysis and prescription. Available on-line.

Schuh, A., \& Caneda, C. (1997). A case for residential schools for economically disadvantaged youth. Residential Treatment for Children and Youth, 14, 1-14.

Sommer, R., \& Witney, G. (1961). The chain of chronicity. American Journal of Psychiatry, 118, 111-117.

Stanton, A.H., \& Schwartz, M.S. (1954). The mental hospital. New York: Basic Books.

Stirling, G., \& Reid, D.W. (1992). The application of participatory control to facilitate patient well-being: An experimental study of nursing impact on geriatric patients. Canadian Journal of Behavioural Science, 24, 204-219. 
Strauss, A., Schatzman, L., Bucher, R., Ehrlich, D., \& Sabshin, M. (1964). Psychiatric ideologies and institutions. New York: Free Press.

Tarullo, A.R., \& Gunnar, M.R. (2005). Institutional rearing and deficits in social relatedness: Possible mechanisms and processes. Cofnitie Creier Comportament, 9, 329-342.

Thomas, W.H. (1994). The Eden Alternative: Nature, hope, and nursing homes. Sherburne, NY: The Eden Alternative Foundation.

Thomas, W.H. (2004). What are old people for? How elders will save the world. Acton, MA: VanderWyk \& Burnham.

Van Biema, D. (1994, December 12). The storm over orphanages. Time, 58-62.

Weisman, M-L. (1994, July). When parents are not in the best interest of the child. The Atlantic Monthly, 43-63.

Weinstein, L.B. (1998). The Eden Alternative: A new paradigm for nursing homes. Activities, Adaptation \& Aging, 22(4), 1-8.

White, W.D., \& Wolfensberger, W. (1969). The evolution of dehumanization in our institutions. Mental Retardation, 7, 5-9.

Wing, J.K. (1962). Institutionalism in mental hospitals. British Journal of Social and Clinical Psychology, 1, $38-51$.

Wing, J.K. (2000). Institutionalism and institutionalization. Journal of Forensic Psychiatry, 11, 7-10.

Wing, J.K., \& Brown, G.W. (1970). Institutionalism and schizophrenia: A comparative study of three mental hospitals, 1960-1968. London: Cambridge University Press.

Wirt, G.L. (1999). Causes of institutionalism: Patient and staff perspectives. Issues in Mental Health Nursing, 20, 259-274.

Wolfensberger, W. (1972). The principle of normalization in human services. Toronto, Canada: National Institute on Mental Retardation.

Wolfensberger, W., \& Glenn, L. (1975). PASS 3: A method for the quantitative evaluation of human services. Toronto: National Institute on Mental Retardation.

\section{Author's Note:}

Address correspondence to: Miriam McNown Johnson, Ph.D., M.S.W., associate dean for Academic Affairs and associate professor, College of Social Work, University of South Carolina, Columbia, SC 29209, USA. e-mail: miriam.johnson@sc.edu. 